\title{
FORMAÇÃO DO ESTADO BRASILEIRO E DEMOCRACIA: LIÇÕES DE FAORO E FERNANDES ${ }^{1}$
}

\section{FORMATION OF THE BRAZILIAN STATE AND DEMOCRACY: LESSONS FROM FAORO AND FERNANDES}

\author{
Leila Maria Bedeschi Costa*
}

\begin{abstract}
RESUMO
Neste artigo argumentamos que a evolução da sociedade brasileira recente pode ser compreendida à luz de seus elementos formadores. Focalizamos, em especial, as análises de dois grandes intérpretes do Brasil - Florestan Fernandes e Raymundo Faoro - sobre a formação do Estado, a qual nos permite discutir a formação de seu outro polo, a sociedade civil, bem como os limites e possibilidades ao avanço da democracia no país.
\end{abstract}

Palavras-chave: Interpretações do Brasil. Democracia. Estado. Sociedade Civil.

\begin{abstract}
This paper argues that it is possible to understand the evolution of Brazilian society in the light of the elements that form it. The paper focuses in particular, the analyses carried out by Florestan Fernandes and Raymundo Faoro about the formation of the State, which contribute to the discussion the formation of civil society, as well as the limits and possibilities to the advancement of democracy in the country.
\end{abstract}

Keywords: Brazil's Interpretation. Democracy. State. Civil society.

\section{Introdução}

Uma das características dos grandes intérpretes do Brasil é o fato de suas obras iluminarem a compreensão da sociedade brasileira atual, ainda que anos após terem sido escritas. "Os donos do poder" de Faoro (FAORO, 2008) e "A revolução burguesa no Brasil", de Florestan Fernandes (FERNANDES, 2005), são obras desta natureza.

Com metodologias distintas e interpretações do país que também diferem, estes trabalhos têm em comum o fato de analisarem a formação do Estado

${ }^{1}$ Trabalho originalmente apresentado no curso "Interpretações do Brasil", oferecido no Doutorado de Economia da Universidade Federal do Rio Grande do Sul (UFRGS).

* Doutoranda em Economia do Desenvolvimento pela Universidade Federal do Rio Grande do Sul (UFRGS), mestre em Economia pela Universidade Estadual de Campinas (Unicamp) e graduada em Economia pela Universidade Federal de Minas Gerais (UFMG). 
brasileiro utilizando o conceito de patrimonialismo. Um focalizando a evolução contraditória, e outro, os elementos de continuidade no modus operandi deste Estado, ambos embasam a compreensão da contraparte do Estado, a sociedade civil brasileira.

Neste artigo, defende-se que os caminhos recentes da democracia brasileira, desde o fim do regime militar, podem ser compreendidos à luz das interpretações desses autores. Tanto os avanços da sociedade quanto a permanência de certas estruturas podem ser compreendidos a partir dos conceitos de mudança com acomodação, patrimonialismo e estamento burocrático.

Neste sentido, realiza-se um exercício de extrapolação, procurando tratar um período distinto daquele analisado originalmente pelos autores, à luz de fatos e conceitos utilizados para um período mais remoto da história do Brasil.

Recorre-se a outros autores, os quais abordam a democracia do possível e o processo de redemocratização no Brasil, em análises que em alguma medida vão ao encontro daquelas dos intérpretes citados.

Deixa-se de lado aqui a discussão mais espinhosa sobre a especificidade ou não do Brasil no tocante à presença dos mecanismos sociopolíticos descritos pelos intérpretes.

$\mathrm{Na}$ primeira parte do artigo são abordados os principais elementos das análises de Faoro e Fernandes sobre a formação de Estado brasileiro. Apresenta-se a visão própria sobre a percepção dos autores acerca da formação da sociedade brasileira, com base na discussão anterior. Utiliza-se para isso o conceito gramisciano de oposição/ unidade entre Estado e sociedade civil, e são destacadas diferenças interpretativas relevantes entre eles.

Em seguida, apresentam-se algumas características da sociedade brasileira após o processo de redemocratização dos anos 80 , procurando estabelecer um diálogo com as visões dos autores.

Conclui-se abordando os riscos e as possibilidades interpretativas do tipo de extrapolação realizada neste exercício.

\section{Principais características do Estado brasileiro em formação}

Para Raymundo Faoro (2005) a formação do Estado no Brasil antecedeu a formação da própria sociedade. A evolução política do país há que ser vista como decorrência do processo de expansão do capitalismo da metrópole, o qual denomina capitalismo político.

Duas peculiaridades da evolução portuguesa teriam sido transplantadas para o Brasil colônia e estariam na base da dinâmica política brasileira ainda hoje: o crescimento da burguesia inserida na estrutura do Estado (portanto de forma não autônoma) e sua contraparte, ou seja, a presença de um estamento burocrático, detentor efetivo do processo decisório.

Do ponto de vista social, não havia diferenciação entre as terras do rei, de sua família e as terras do Estado. Os nobres por sua vez tinham posse, mas não domínio político sobre as terras, e eles eram considerados como uma espécie de funcionários do rei. Segundo o autor, não houve feudalismo em Portugal no sentido típico. A partir do século $\mathrm{XV}$ o rei constituiu-se no principal burguês, uma vez que toda atividade comercial lucrativa era por ele organizada ou outorgada. Longe de ser uma economia tipicamente agrária, foi no grande comércio ultramarino que a nação portuguesa se firmou, centralizando-se precocemente em relação a outras nações europeias.

A conversão dos negócios capitalistas em questão de Estado teve como desdobramento essa centralização de Portugal, que, impulsionada por guerras, foi condição necessária para seu precoce desenvolvimento capitalista. Esgotadas as possibilidades dentro da fronteira, a exploração econômica e a concessão de terras no Brasil darão continuidade ao mesmo modelo. O Estado aqui e em Portugal avançou para além da sociedade civil, estrutura que perdurou até o século XX.

Como consequência política deu-se a fragilização da própria burguesia face ao grupo de funcionários públicos detentores dos favores reais e capazes de imprimir os rumos do processo político autonomamente, pois eram, no início, encarregados da administração dos bens do rei e, em seguida, de todo o reino. Socialmente, foi retardada a formação do espírito capitalista e de seus procedimentos típicos, apesar do uso do dinheiro nas transações.

Configuram-se diversas características típicas do capitalismo, mas não se traça o caminho para a industrialização. Há organização da sociedade em torno do interesse econômico (enriquecimento e grandeza da nação), emergência da classe burguesa, 
atividades racionalmente orientadas a um fim, a racionalização administrativa (a serviço da guerra e da conquista), formação da burocracia dedicada à coisa pública, monetização das relações comerciais, aceitação do lucro como finalidade da atividade econômica. Não é a livre empresa que se firma, nem o interesse individual que determina em quais atividades vai-se investir. Toda a atividade econômica é concessão régia, ou explorada diretamente pela Coroa (as excepcionalmente lucrativas o são). Não há ideologia que assimile o lucro ao resultado do esforço pelo trabalho. O Estado é o regulador e também sócio - parte dos lucros lhe é entregue. Empresários não se orientam por livre iniciativa, mas por concessões reais. Somente prosperam as atividades que têm o rei como sócio. E de toda forma, a opção por tornar-se funcionário real pode ainda ser mais lucrativa.

Há a burocracia dedicada ao serviço público. Mas ela pouco se assemelha ao aparato neutro e racional de Estado tipificado por Weber. Cargos são obtidos por barganha, favores reais. Atendem aos privilegiados e não ao interesse público no sentido moderno do termo. Este "estamento burocrático" afasta-se paulatinamente do modo típico de poder da nobreza - o prestígio advindo da condição de nascimento. Soma-se à nobreza no hábito de um consumo luxuoso, alimentado por importações, que se sustentam por uma economia local predominantemente especulativa.

Esgotadas as possibilidades de sustentar este padrão de vida e de engrandecimento da nação no próprio território, esta estrutura é transplantada além das fronteiras, para a colônia brasileira. E assim o Estado precede a nação, a sociedade civil. A partir das capitanias, com Tomé de Souza, a racionalidade pré-moderna do Estado português (CAMPANTE, 2003) instaura-se. Toda a estrutura administrativa volta-se para o objetivo de bancar o interesse português, forjando uma sociedade. Enquanto representantes do rei e de seus próprios interesses, os membros da Corte ocupam o território, protegidos pela legislação colonial.

Finda a colônia, permanece o Estado centralizador, impositivo portador de um projeto de desenvolvimento que ele próprio empreende e outorga aos grupos sociais.

Faoro reconhece a sociedade brasileira como sociedade de classes. Entretanto, numa perspectiva culturalista, salienta que o exercício do poder aqui predominante ultrapassa relações de classe. Prestígio e diferenciação social advêm de relações privilegiadas com o estamento burocrático, e isto é fundamentalmente distinto do que ocorre nas sociedades de classes.

Segundo Campante (2003), para Faoro, teríamos adotado o capitalismo em sua racionalidade técnica, tanto na atividade privada quanto na gestão pública. No último caso, apenas formalmente (direito, planejamento). Mas não lhe adotamos o espírito. Não haveria uma racionalidade legal, universal em curso, mas uma racionalidade que se conformaria a interesses privados, portanto casuísta. Não é a livre empresa que cultuamos, mas aquela capaz de absorver favores do Estado. Não é a burocracia racional que temos, mas aquela que opera em prol de grupos específicos.

Há momentos da história do país em que o projeto de Estado parece autonomizar-se, dando razão à visão de Faoro, impondo-se inclusive sobre frações da classe dominante - como no Estado Novo ou no Regime Militar originado em 1964.

A contrapartida do Estado centralizado e entregue a esse estamento burocrático é a heteronomia da sociedade nascente. Poder-se-ia concluir que Faoro identifica na sociedade assim formada uma fragilidade endêmica.

Alguns autores contestam a percepção de Faoro de que o patrimonialismo presente na estrutura política brasileira seria uma especificidade herdada da história portuguesa, permanecendo imutável em essência. Simon Schwartzman (2006) entende que na perspectiva weberiana este é um traço das sociedades tradicionais, inclusive orientais, que tende a desaparecer com a modernidade. Ângela Chieza (2006) questiona se a perspectiva negativista em relação à predominância do Estado sobre a sociedade civil, característica da visão do autor, não seria consequência de ter como referência a evolução da sociedade americana. Lembra que em outras sociedades houve predominância do Estado na formação da nação, sem que isto implicasse atraso.

Faoro não está isolado em sua percepção negativa sobre a repetição histórica no processo político brasileiro. Dubrun (1983) aborda a conciliação como importante mecanismo político reiteradamente empregado na sociedade. O conceito de conciliação 
é tomado pelo autor distintamente do entendimento comum, que pressupõe acerto entre grupos sociais igualmente potentes. O termo é empregado entre aspas, significando de fato estratégia de dominação. Tal mecanismo entra em cena sempre que há iminentes transformações a favor dos segmentos mais vulneráveis da sociedade e opera concedendo mudanças que não chegam a afastar do núcleo decisório os grupos dominantes de sempre. Instrumento utilizado para aplacar conflitos, combina-se alternativamente com dois outros que têm os mesmos propósitos, mas que vêm à tona em momentos em que a elite política sente-se mais ameaçada: o autoritarismo mobilizador e o autoritarismo desmobilizador. O primeiro implica a elaboração de projetos de país pelo segmento da elite dissidente. Exemplo do primeiro: o projeto desenvolvimentista do ISEB (Instituto Superior de Estudos Brasileiros), criado em 1955, vinculado ao Ministério de Educação e Cultura, mas com autonomia administrativa e de pesquisa e desativado após 1964 . Do segundo, o golpe de 64 é boa ilustração. Em ambos os casos - conciliação e autoritarismo - outorga-se da elite para o restante da nação uma concepção e práticas do fazer político.

Debrun identifica tal procedimento como um desdobramento da forma de constituição do país - algo herdado do mecanismo de apropriação das terras, do poder exercido pelos senhores. O passado colonial constituiu um fosso social de dimensões mais profunda entre elite e o restante da sociedade. Maior que o existente entre sociedades de classes de passado não colonial. Benesses foram utilizadas ao longo de toda história para reduzir pressões da grande massa de dominados. Do senhor de terras que apadrinhava os empregados à incorporação ao poder de lideranças dissidentes. O mesmo mecanismo estaria presente no processo de distensão do governo Geisel, analisado por ele na obra (DEBRUN, 1983). Conclui o autor que a conciliação, ao invés de ser uma característica positiva da sociedade brasileira, uma habilidade para lidar com diferenças, revelaria uma incapacidade de a sociedade transformar-se.

Partilha, portanto, do mesmo fatalismo da "viagem redonda" de Faoro. Haveria um Estado, permanentemente refém ou ocupado por grupos de interesse que dele não se afastam. Diferentemente de Faoro que vê neste grupo de donos de poder certa autonomia em relação à classe dominante, Debrun o identifica como representação desta própria classe.

O ponto de partida de Fernandes (2005) é outro, tanto teórica quanto metodologicamente. Dir-se-ia que não vê uma viagem redonda, mas uma sociedade que avança em espiral, combinando transformações e permanências, ou, em seus termos, mudança com acomodação. Considerado pai da sociologia crítica no Brasil desenvolve abordagem dialética da história do Brasil - busca as unidades de contrários e leis de movimento da sociedade. Mas o faz atento às especificidades de nossa história. Busca o sentido de movimento da história, mas também seus sujeitos típicos, combinando de forma então única influências de Hegel, Marx e Weber (CHIEZA, 2006).

Não busca, como os anteriores, estruturas ou modos de agir políticos que sejam permanentes, ou essenciais. Identifica processos de mudança da sociedade, analisando o sentido de construção do Estado e da sociedade brasileira. Mas, como Faoro, nota a permanência do estamento e o descompasso, singular do capitalismo brasileiro, entre evolução social, econômica e política.

Percebe a sociedade como de classes e em "A Revolução Burguesa no Brasil" defende que à época em que escreve (anos 60 e 70, século XX) o processo da revolução burguesa já se teria completado. Isto não se dera de forma concentrada no tempo, tampouco articulando simultaneamente transformações econômicas e sociais às mudanças no poder.

Seria possível reconhecer na história do Brasil um desenvolvimento na direção do capitalismo e da hegemonia burguesa, mas isso não através de uma ruptura inequívoca, nem concentrada no tempo. Ruptura e acomodação combinam-se no processo. Teríamos aqui um capitalismo peculiar. Para compreender isto, sugere evitar conclusões apressadas como equiparar o senhor de engenho ao burguês, simplesmente por coordenar uma atividade voltada ao mercado, ou o escravo moderno ao servo.

O capitalismo aqui teria antecedido a ordem social competitiva. Embora o núcleo relevante da economia tivesse estreitos vínculos com o mercado internacional, a condição política de colônia e a condição social de uma ordem estamental e escravocrata limitariam a plena constituição do "nosso" capitalismo.

Móveis capitalistas ou forças produtivas capitalistas nos setores chave (monocultura exportadora, 
comércio internacional) combinavam-se ao patrimonialismo das relações de poder - autoridade privada e posteriormente burocrática dos senhores de terra e relações de trabalho escravas. O processo da revolução burguesa teria transformado lenta, contraditória e persistentemente a sociedade brasileira em capitalista. Mas todo o tempo houve entraves fundamentais à instauração da ordem competitiva e, portanto, também da democracia sob a hegemonia burguesa.

Chieza (2006) identifica na obra "A Revolução Burguesa no Brasil" os descompassados momentos da transformação. Sucedem-se transformações na ordem política, econômica, sociocultural e socioeconômica, as quais se estendem no tempo, o que torna difícil identificá-las como uma revolução.

A transformação política teria dado início à mudança, com o fim do exclusivo colonial, que abre mercado e posteriormente a independência, que traz a possibilidade histórica de que o país seja governado por brasileiros. Como decorrência, abriu-se o caminho da transformação na esfera econômica, com a emergência de moeda e políticas econômicas próprias, permanência do excedente econômico no próprio território, sob controle de grupos do país.

Esta mudança daria oportunidade para o surgimento de um novo tipo, o empreendedor. O comerciante - importador e exportador - agora orientado pelo autointeresse, exclusivamente, e o empresário-fazendeiro, introduzindo o cálculo racional na atividade agrícola, passaria a demandar instrumentos técnicos melhores, dinamizando o mercado local. Também exigiria outro tipo de relações de trabalho, mais afeitas à produtividade, estimulando a imigração.

O aprofundamento da ordem capitalista tornarse-ia progressivamente incompatível com a ordem social vigente. República e abolição removeram os últimos entraves à constituição do mercado, generalizando a mercantilização das relações de trabalho, o que complementou a mercantilização das terras.

Mas a cada um destes passos históricos distantes no tempo o mecanismo de acomodação se impunha. Antes que as contradições do exclusivo colonial se extremassem, a vinda da família real se apresentaria como solução. À abdicação seguiu-se a regência, não a imediata proclamação da República. Imigração europeia e a Lei de Terras resolveram a necessidade de mão de obra no núcleo mais avançado, antes da abolição. Foram os elementos oriundos do senhorio e os estratos médios por eles protegidos que inicialmente ocuparam os novos espaços políticos e cargos burocráticos que surgiram com a independência. Estes mecanismos de acomodação camuflariam a persistente transformação na direção do capitalismo.

Até a filosofia liberal, considerada pelo autor uma importante força propulsora de mudança, ganharia no país cores próprias. Não se contrapunha à prevalência da escravidão e, no plano internacional, implicava aceitação da inserção subordinada do Brasil ao capitalismo mundial. Livre comércio e especialização em primários, bem como direito à propriedade justificavam grandes lavouras e escravidão, em princípio. Por outro lado, esta mesma ideologia impulsionou um projeto de independência nacional, de país. Projeto que associou modernidade à república e finalmente ao trabalho livre.

Houve um sentido, mas ele não se fez inexorável. O espírito capitalista, no sentido weberiano, consolidou-se aos poucos, sendo difícil afirmar que se impôs de modo definitivo. Antes conviveu com relações de autoridade tradicional, com mentalidade de privilégios aos antigos proprietários de terra e detentores de poder político.

Ao longo deste processo a burguesia constituiu-se como classe e foi construindo sua hegemonia. Mas não o fez de modo autônomo ou através da tomada do poder de golpe. Ao contrário, foi-se utilizando do Estado, das estruturas existentes. Aceitou primeiramente o Império, antes da República. Os agentes da mudança não necessariamente se opuseram de forma violenta aos antigos detentores do poder (como no modelo "clássico" de revolução burguesa). Conviveram com a aristocracia agrária, deixando-lhe intocado o domínio sobre regiões rurais. Urbanização e industrialização mais tarde se darão sem o recurso à reforma agrária. A "unificação" promovida pelo Golpe de 30 favorecia a burguesia, pouco importando a forma autoritária de exercício do poder. Segundo Tótora (1999) a democracia apenas lhe interessaria de modo instrumental.

A acomodação a velhas estruturas, que tira da burguesia o caráter revolucionário das relações sociais, típico das revoluções burguesas "clássicas", explica-se pela sua origem: parte da burguesia teve base agrária e originou-se da própria classe dos senhores; parte dos senhores dedicados à exportação 
de café converteu-se em capitalista - em meados do século XIX, no planalto paulista. Papel relevante teve o imigrante descapitalizado na formação da outra ponta, a classe trabalhadora. Sua vinda em massa combinada à restrição do acesso à terra cumpriu o papel originalmente desempenhado pelos "cercamentos". A condição de inserção desta população migrante à atividade agrícola - pagando aos proprietários pelo translado - restringiu ou adiou as manifestações de conflito.

Enquanto as relações sociais conformaram-se desta maneira, difundiram-se lógica e práticas capitalistas na esfera econômica. Adotaram-se modernas técnicas, ocupando a terra por um princípio de racionalidade, formando mercados locais em torno da região mais dinâmica. No final dos anos 30, a ordem competitiva se completou no Brasil.

Mas este capitalismo é específico, porque dependente - subordinado nas relações internacionais a outras nações capitalistas. Esta última especificidade também condiciona o avanço da ordem social que se estabelece sob a hegemonia burguesa. A posição subordinada da burguesia nacional na ordem capitalista faria com que ela impusesse dentro do país a manutenção de uma enorme distância social dos não proprietários (superexploração). Segundo Tótora (1999), Florestan não procurou inovar, tendo adotado a Teoria da Dependência já existente, mas sua abordagem demonstraria a incapacidade da burguesia brasileira para instaurar uma democracia sob sua hegemonia.

A acomodação como mecanismo político em Fernandes vai ao encontro da conciliação de Debrun ou da permanência do estamento burocrático no poder, de Faoro. Enquanto os dois primeiros identificam nos movimentos de nossa própria história este instrumento de continuidade, Faoro o vê como transplantado da metrópole. Conclusão de sua longa incursão pela história do Estado português.

Dos três autores, Fernandes se distingue por abordar a história como processo, logo em inerente transformação. Procura-lhe o sentido do movimento, ainda que algumas estruturas persistam por longos períodos.

Distintas, mas não irreconciliáveis, estas análises podem contribuir para a compreensão tanto das mudanças quanto das continuidades identificáveis na história brasileira.

\section{Democracia possível e as lições de Faoro e Fernandes}

A análise da formação do Estado no Brasil, foco das obras "Os donos do poder" e "A Revolução Burguesa no Brasil”" pode iluminar a compreensão sobre a democracia no país. Este é o objetivo desta seção e será cumprido somente com base nos elementos explicativos trazidos pelas obras de referência, ainda que cada um dos autores tenha emitido considerações sobre o tema em escritos e entrevistas diversas. Com isso, reforça-se a hipótese de que boas interpretações sobre a formação do país ajudam na compreensão do presente.

Dois conceitos são necessários para que se possam estabelecer pontos de contato entre as interpretações do Brasil em foco e a questão democrática: sociedade civil e democracia. Segue uma breve abordagem, apenas suficiente para os objetivos aqui definidos.

Segundo Carlos Nelson Coutinho (1999), em Gramsci, a sociedade civil forma com o Estado um par conceitual, uma dicotomia que implica unidade na diversidade, em que o Estado representa a face política, coercitiva desta sociedade. Paralelamente, a sociedade civil, que poderia ser compreendida como a esfera privada em contraposição à pública representada pelo Estado, não é monolítica. Consiste no espaço privilegiado da luta de classes, conquanto nela se contraponham os interesses de proprietários e não proprietários de capital diante do mercado. Estabelece com o Estado uma relação dialética, na medida em que é na esfera pública que se arbitram as normas que enfim definirão a hegemonia política de um grupo de interesses sobre outros. O par conceitual, que integra a denominada superestrutura, em linguagem marxista, ganha centralidade na análise de Gramsci.

Coutinho (1999) destaca a relevância de se evitar a visão distorcida que, segundo ele, predominou no Brasil pós-ditadura, quando a sociedade civil (identificada como oposição à militar) foi tomada como despolitizada e intrinsecamente positiva, enquanto que Estado (identificado com ditadura) era percebido como intrinsecamente negativo. Decorre daí uma visão maniqueísta da realidade, segundo a qual a sociedade civil é percebida como homogênea em seus interesses, lutando contra o Estado opressor, 
posição assumida pelos ideólogos neoliberais nos anos 80 .

É por dar realce ao aspecto político-histórico, que acompanha a dimensão tipicamente econômica do capitalismo, que este conceito faz-se necessário aqui. As interpretações do Brasil em análise têm em comum a abordagem da especificidade do nosso capitalismo, o que se manifesta na trajetória política e evolução cultural.

A distinção entre sociedade civil e Estado conduz à problemática de como se estabelecem as relações entre esfera pública e esfera privada; de como a sociedade de indivíduos se regularia por uma esfera comum e ao mesmo tempo distinta de cada indivíduo ou grupo de interesses. A democracia seria uma das formas de estabelecer este relacionamento.

A forma democrática seria a não violenta, não autoritária e baseada em normas e procedimentos. Norberto Bobbio (1992) afirma que uma definição mínima de democracia envolve três elementos ideais: um grande número de indivíduos da sociedade participa do processo decisório vinculatório (normas válidas a toda a sociedade); as decisões são tomadas com base em regras e procedimentos previamente pactuados, dos quais a regra da maioria é a mais relevante; finalmente, os indivíduos que decidem o fazem diante de opções reais e, para tal, liberdade de escolha, opinião, expressão são fundamentais. Sendo condições ideais, não existem plenamente em nenhum país do mundo. Caminha-se no sentido da democracia quando se verifica a ampliação de cada uma delas: um aumento do número dos envolvidos (direito a voto), procedimentos claros e gerais, pluralidade de escolhas, informação.

Visto desde sua origem, o Brasil claramente avançou na construção da democracia real, no sentido defendido por Bobbio. A perspectiva histórica trazida por Faoro e Fernandes contribui para reflexão sobre o alcance do processo.

Claramente, o patrimonialismo, identificado como traço histórico brasileiro pelos dois autores, antagoniza com a evolução da democracia, no sentido apresentado acima, uma vez que significa justamente a indiferenciação entre esfera pública e privada. Resta investigar se ainda prevalece nos processos recentes.

É possível identificá-lo seja no desenrolar de fatos políticos específicos, seja na cultura de relacio- namento sociedade-Estado. Ainda hoje representantes políticos eleitos, em especial nas regiões Norte e Nordeste do país, tratam tanto o processo eleitoral quanto a ocupação de cargos do poder público como negócio familiar, constituindo "dinastias" políticas e fazendo acompanhar a sua vida como pessoa pública do crescimento do seu patrimônio pessoal. Sucedem-se casos de investigação a respeito de ex-ocupantes do poder público que no momento seguinte ao retorno às relações de mercado beneficiaram-se de informações e relacionamentos proporcionados pela participação no governo.

$\mathrm{O}$ acesso a privilégios em decorrência do pertencimento a grupos específicos é bastante nítido entre nós. Disto são exemplos: o julgamento em tribunais especiais para juízes e militares, a extensão da imunidade parlamentar para casos de crimes comuns, a fixação das próprias remunerações pelos parlamentares e a concessão de cárcere especial para portadores de diplomas universitários.

Num sentido mais amplo e atinente às percepções de Faoro, diversos grupos econômicos brasileiros e estrangeiros instalados no país lograram obter suas atuais posições nos respectivos mercados em decorrência direta de seu relacionamento com o governo nacional. Ainda que se alegue que este expediente integrou a estratégia de desenvolvimento do país, não se pode negar que os casos de grupos econômicos bem sucedidos fora da esfera do relacionamento com o poder público são bastante raros no Brasil.

A presença destes processos, ainda que sob a vigência dos procedimentos formais da democracia - eleições diretas, concurso público para ocupação de cargos públicos, publicidade na execução orçamentária -, empalidece e esvazia de conteúdo os mecanismos democráticos.

O mecanismo de mudança com acomodação, identificado por Fernandes, é perceptível em processos políticos recentes.

Antes de discuti-los especificamente, vale salientar a observação de Tótora (1999) sobre a concepção de democracia em Fernandes. Segundo ela, fiel à sua interpretação da sociedade como sociedade de classes, o autor diferenciaria democracia burguesa de democracia operária ou socialista. Ao afirmar que a burguesia teria perdido a oportunidade de construir uma verdadeira democracia sob sua hegemonia - um 
estado de direito pluriclassista -, Fernandes (2005) também traz a possibilidade de que o projeto democrático seja conduzido pela outra classe. Ele, tal qual Debrun (1983), perceberia no Estado brasileiro mais a expressão dos interesses do grupo dominante do que o espaço da negociação entre interesses de classe.

Feita tal consideração, nota-se que o avanço com acomodação revela-se em ao menos três processos políticos recentes: a distensão do final do Regime Militar, o processo constituinte e a eleição do Presidente Lula.

O processo de abertura política dos anos 80 , ao final do Regime Militar, foi caracterizado por uma política de distensão, liderada por uma fração do próprio exército. Foi seguida de um processo de anistia que abrangeu os dois polos em disputa e ainda por uma última eleição indireta de "transição". A conciliação ou mudança com acomodação revelou-se claramente na composição da chapa ao colégio eleitoral, combinando um dos líderes da oposição ao regime militar com uma importante liderança da base de sustentação ao referido regime. O governo resultante foi marcado pela consolidação do processo eleitoral democrático e ainda pela escolha de uma prioridade política que não acirrava os conflitos - combate à inflação - embora tivesse maior impacto sobre os segmentos menos privilegiados da sociedade.

Na sequência destes acontecimentos, o processo constituinte consolidaria a regra do jogo democrático formal, tendo cristalizado alguns dos elementos ícones do avanço com acomodação. São incluídos instrumentos de proteção do indivíduo contra o Estado. Consideram-se livre iniciativa e propriedade privada como pilares da ordem econômica, ao mesmo tempo em que é estabelecida uma série bastante ampla de direitos sociais, vistos como deveres do mesmo Estado.

Do ponto de vista político, o reconhecimento das entidades sindicais, bem como de uma série de direitos necessários ao exercício de atividades representativas demonstram um avanço democrático.

Do ponto de vista econômico, ou dito de outro modo, da continuidade do avanço capitalista no Brasil, a nova constituição bem como o sucesso posterior dos processos de combate ao endividamento externo e inflação trazem condições ambientais para um novo impulso.

No período ainda mais recente, o avanço com acomodação revela-se uma vez mais na eleição de Lula à presidência (2002). Desde a aliança que o conduziu à vitória eleitoral até o desenvolvimento dos programas de governo nos dois mandatos, que combinam avanços sociais (distribuição de renda e ampliação das políticas sociais) com o comando do núcleo duro da economia segundo interesses empresariais.

Nenhum dos privilégios descritos anteriormente como resquícios do patrimonialismo foi removido. Também não se avançou em políticas de progressividade tributária ou democratização do acesso à terra. Igualmente, antigas reivindicações do movimento sindical, tais como redução da jornada semanal de trabalho e restrição à demissão imotivada, por exemplo, mantiveram-se intocadas.

\section{Conclusões}

Neste artigo defendeu-se que os conceitos empregados pelos intérpretes do Brasil nos anos anteriores podem ser muito relevantes para compreender o país de hoje.

Elegeram-se obras de autores que enfatizam o processo de formação do Estado brasileiro - Raymundo Faoro e Florestan Fernandes - para realizar uma reflexão sobre o avanço da democracia no Brasil.

Embora discordando sobre o método e mesmo sobre a interpretação, há importantes pontos de convergência na visão do Brasil de Faoro e Fernandes. A principal delas, a abordagem do caso brasileiro como específico, a despeito de cada um ter um arcabouço teórico próprio como fundamento, consideram a história do país, mas não são historicistas.

Conclui-se que, embora haja avanços, a dinâmica atual da vida política do país ainda permanece marcada pelos mecanismos de mudança com acomodação e ocupação patrimonial do Estado. Uma série de práticas, comuns (quero a concordância com a ideia) ao relacionamento de indivíduos e empresas com o Estado, revela a prevalência do patrimonialismo. Fenômenos como abertura política, formulação da nova constituição e eleição de Lula demonstram o mecanismo de mudança com acomodação.

As conclusões a que se chegou basearam-se 
apenas numa tentativa de estender as percepções dos autores de referência sobre o passado para situações presentes. Não foram consideradas, portanto, novas avaliações e obras dos mesmos autores, produzidas posteriormente.

Isto é consistente com a hipótese inicial sobre a robustez das interpretações escolhidas. Entretanto, representa um risco teórico. Cada um dos fenômenos e processos citados como exemplos mereceriam cuidadosa análise, dada sua complexidade. Os próprios autores, de cujos conceitos este trabalho se apropriou, provavelmente formulariam outra e mais complexa interpretação para cada um. Zelosos dos aspectos da realidade concreta, certamente teriam uma série de considerações a fazer, com possível revisão, inclusive, do que tinham dito anteriormente sobre o passado do país.

Acredita-se que a despeito dessas considerações, o exercício permanece válido, conquanto se possa entender que a utilização da abordagem dos autores eleitos a outras situações consistiria numa primeira aproximação, um exercício de buscar unidade de compreensão, em um objeto tão complexo quanto a interpretação de um país.

Um ponto da análise merece maior investigação. Ambos os autores em foco parecem sugerir certa fragilidade na sociedade civil brasileira face ao Estado. Faoro por supor a dominação do poder pelo estamento burocrático, Fernandes por enxergar a burguesia nacional como amalgamada ao Estado, o que revelaria a um só tempo sua fragilidade e seu senso de interesse.

A despeito desta vulnerabilidade quase endêmica, alguns dos avanços da sociedade civil vieram, ainda que de forma contraditória nos processos recentes descritos. Estaríamos escapando à condenação histórica?

\section{Referências}

BOBBIO, N. O futuro da democracia: uma defesa das regras do jogo. São Paulo: Editora Paz e Terra, 1992. Tradução Marco Aurélio Nogueira.

CAMPANTE, R. G. O patrimonialismo em Faoro e Weber e a sociologia brasileira. Dados, vol. 46, n.1. Rio de Janeiro: IUPERJ, 2003. p.153-193.

CHIEZA, R. A. A constituição do Estado brasileiro nas visões de Florestan Fernandes e Raymundo Faoro: uma comparação. XXIV Encontro Sociedade de Economia Política. 2006. Disponível em: <http.www. sep.org.br>. Acesso em dez. 2011.

COUTINHO, C. N. Apresentação. In: SEMERARO, G. Gramsci e a sociedade civil. Petrópolis: Vozes, 1999.

DEBRUN, M. A conciliação e outras estratégias. São Paulo: Editora Brasiliense, 1983.

FAORO, R. Os donos do poder: formação do patronato político brasileiro. São Paulo: Editora Globo S.A., 2008. Edição Comemorativa.

FERNANDES, F. A revolução burguesa no Brasil: ensaio de interpretação sociológica. 5.ed. São Paulo: Editora Globo S.A, 2005.

SCHUWARTZMAN, S. Notas sobre o patrimonialismo e a dimensão pública na formação da América Latina contemporânea. 2006. Disponível em: <http.www. schwartzman.org.br>. Acesso em dez. 2011.

RAMOS, L.C.S. A sociedade civil em tempos de globalização: uma perspectiva neogramisciana. Dissertação (Mestrado). PUC Rio: 2005. Disponível em: <http.www2. dbc.puc-rio.br>. Acesso em: dez. 2011.

TAVARES, P. V.; FONSECA, P.C.D. Estamento burocrático e intencionalidade: Raymundo Faoro, Florestan Fernandes. Revista de Economia Política e História Econômica, n.16, jan/2009, p. 56-74.

TÓTORA, S. A questão democrática em Florestan Fernandes. Lua Nova, n.48, 1999. p. 109-24.

Recebido em: 2 de agosto de 2012 Aceito em: 17 de setembro de 2012 